\title{
openheart Association of Life's Simple 7 and presence of cardiovascular disease in general Australians
}

\author{
Yang Peng, Zhiqiang Wang
}

\begin{abstract}
- Additional material is published online only. To view please visit the journal online (http://dx.doi.org/10.1136/ openhrt-2017-000622).
\end{abstract}

To cite: Peng Y, Wang $Z$. Association of Life's Simple 7 and presence of cardiovascular disease in general Australians. Open Heart 2017;4:e000622. doi:10.1136/ openhrt-2017-000622

Received 24 February 2017 Revised 24 April 2017 Accepted 13 June 2017

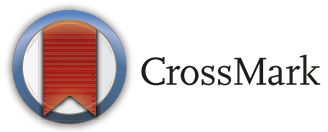

Faculty of Medicine, Centre for Chronic Disease, University of Queensland, Herston, Australia

Correspondence to Dr Yang Peng; y.peng@uq. edu.au
ABSTRACT
Objective The American Heart Association developed Life's Simple 7 to define and monitor cardiovascular health (CVH), but their contributions to cardiovascular disease (CVD) in general Australians are still unclear. Our study aimed to evaluate the separate and combined effects of Life's Simple 7 on CVD among Australians.

Methods We performed a cross-sectional study based on 7499 adults ( $\geq 18$ years) who have been tested for total cholesterol and fasting plasma glucose as part of the 2011-2012 Australian Health Survey. Poisson regression analyses were used to estimate the incidence rate ratios and population attributable fractions of those metrics to CVD prevalence. Participants were classified into three CVH status groups based on the number of ideal metrics: inadequate (0-2), average (3-4) and optimal (5-7). Logistic regression analyses were performed to illustrate the relationships between overall CVH and CVD prevalence.

Results 2100 (21.0\%) participants were having CVD. Smoking, elevated body mass index, blood pressure, total cholesterol, fasting plasma glucose and physical inactivity were observed as significant indicators of CVD. Compared with the inadequate category, participants in the optimal and average category have a $66 \%$ (adjusted OR, 0.34; $95 \% \mathrm{Cl} 0.22$ to 0.54 ) and a $33 \%$ (adjusted OR, $0.67 ; 95 \% \mathrm{Cl} 0.56$ to 0.81 ) lower CVD risk. One more ideal metric was associated with a $21 \%$ reduced CVD risk (adjusted OR, 0.79; 95\% Cl 0.73 to 0.84).

Conclusions We have identified several modifiable risk factors and contributors of CVD in general Australians. The improvement of overall CVH may also reduce CVD risk.

\section{INTRODUCTION}

Cardiovascular disease (CVD) is still a leading cause of mortality, and in 2013 it contributed to over 0.8 million deaths in the USA. ${ }^{1}$ According to the Global Burden of Disease Study, CVD accounted for more than $30 \%$ global overall deaths in $2013 .^{2}$ In Australia, CVD is also one of the major contributors to mortality. Ischaemic heart disease, the most common type of CVD, ranked as the first cause of mortality among Australians. ${ }^{3}$

To define and monitor cardiovascular health $(\mathrm{CVH})$ in general Americans, the American Heart Association released seven modifiable cardiovascular behaviours
KEY QUESTIONS

What is already known about this subject?

- Life's Simple 7 is associated with the cardiovascular disease (CVD) risk in the USA and some other regions. The magnitudes of individual and/or combined effects of Life's Simple 7 varied across studies.

What does this study add?

- Most factors of the Life's Simple 7 and the overall cardiovascular health were significantly related to CVD risk in general Australians.

How might this impact on clinical practice?

- Life's Simple 7 is an easily implementable tool in clinical practice. Hence, doctors and other professionals can provide CVD prevention tips to patients based on their Life's Simple 7 status.

(including smoking status, body mass index (BMI), physical activity and dietary pattern) and factors (including smoking status (also treated as a behaviour), total cholesterol (TC), blood pressure and fasting plasma glucose (FPG)), and they are also called Life's Simple $7{ }^{4}$ To date, a number of studies have examined the individual and combined effects of Life's Simple 7 on CVD risk in the USA, ${ }^{5-7}$ Finland, ${ }^{8}$ China ${ }^{9}$ and Korea, ${ }^{10}$ while the relationship between those factors and CVD risk in general Australian population is still unclear.

The present study used an Australian representative sample collected from the Australian Health Survey (AHS), aiming to clarify the individual and combined associations between Life's Simple 7 and CVD prevalence.

\section{METHODS}

\section{Study design and subjects}

We retrospectively analysed data from the core sample of the 2011-2012 AHS, a nationwide and population-based combined sample of three surveys: National Health Survey (NHS), National Nutrition and Physical Activity 


\begin{tabular}{|c|c|c|}
\hline Factors & Ideal & Unideal \\
\hline Smoking & Never smokers & Current and former smokers \\
\hline Body mass index & $<25 \mathrm{~kg} / \mathrm{m}^{2}$ & $\geq 25 \mathrm{~kg} / \mathrm{m}^{2}$ \\
\hline Physical activity* & $\begin{array}{l}\geq 150 \mathrm{~min} / \text { week moderate or } \geq 75 \mathrm{~min} / \text { week vigorous } \\
\text { or } \geq 150 \mathrm{~min} / \text { week moderate }+ \text { vigorous }\end{array}$ & $\begin{array}{l}<150 \mathrm{~min} / \text { week moderate, }<75 \mathrm{~min} / \text { week vigorous } \\
\text { and }<150 \mathrm{~min} / \text { week moderate + vigorous }\end{array}$ \\
\hline Dietary pattern $†$ & $\begin{array}{l}\text { Having met the fruits and vegetables intake requirement } \\
\text { defined by } 2013 \text { Australian Dietary Guidelines }\end{array}$ & $\begin{array}{l}\text { Having not met the fruits and vegetables intake } \\
\text { requirement defined by } 2013 \text { Australian Dietary Guidelines }\end{array}$ \\
\hline TC & $\begin{array}{l}\mathrm{TC}<200 \mathrm{mg} / \mathrm{dL} \text { and not taking cholesterol-lowering } \\
\text { medication }\end{array}$ & $\begin{array}{l}\mathrm{TC} \geq 200 \mathrm{mg} / \mathrm{dL} \text { and/or taking cholesterol-lowering } \\
\text { medication }\end{array}$ \\
\hline Blood pressure & $\begin{array}{l}\text { Systolic blood pressure }<120 \mathrm{~mm} \mathrm{Hg} \text { and diastolic blood } \\
\text { pressure }<80 \mathrm{~mm} \mathrm{Hg}\end{array}$ & $\begin{array}{l}\text { Systolic blood pressure } \geq 120 \mathrm{~mm} \mathrm{Hg} \text { and/or diastolic } \\
\text { blood pressure } \geq 80 \mathrm{~mm} \mathrm{Hg}\end{array}$ \\
\hline Fasting plasma glucose & $<100 \mathrm{mg} / \mathrm{dL}$ & $\geq 100 \mathrm{mg} / \mathrm{dL}$ \\
\hline
\end{tabular}

${ }^{*}$ Moderate physical activity refers to any exercise that caused a moderate increase in heart rate or breathing (eg, gentle swimming, social tennis, golf). Vigorous physical activity refers to any exercise that caused a large increase in heart rate or breathing (eg, jogging, cycling, aerobics, competitive tennis).

†The 2013 Australian Dietary Guidelines recommended at least 2 serves of fruits for all adults, 5 serves of vegetables for men aged over 70 and all women, 5.5 serves of vegetables for men aged between 51 and 70 , and 6 serves of vegetables for men aged 50 or younger.

TC, total cholesterol.

Survey (NNPAS), and National Health Measures Survey (NHMS), which included participants from the first two surveys who provided biomedical samples. The Australian Bureau of Statistics (ABS) organised the three surveys. NHS and NNPAS used a stratified multistage random sample from private dwellings usual residents in urban and rural areas of all states in Australia, covering about 97\% of the people living in Australia. Overseas visitors staying or intending to stay in Australia for 12 months or more are in scope. Households in very remote areas of Australia and discrete Aboriginal and Torres Strait Islander communities were excluded. Trained interviewers obtained the NHS and NNPAS information through faceto-face, computer-assisted personal interview. For the 24-hour dietary recall collection, computer-assisted telephone interview was used. All participants aged 12 or over and aged 5 or over in both NHS and NNPAS were asked to voluntarily provide fasting blood samples and urine samples, which constituted the NHMS, to the convenient collection centres, and Sonic Healthcare processed the samples. The current NHS was the sixth in a series of regular population surveys, and the previous ones were conducted in 1989-1990, 1995, 2001, 2004-2005 and 2007-2008. NNPAS and NHMS were new surveys. NHS, NNPAS and NHMS were enumerated from 6 March 2011 to 17 March 2012, 29 May 2011 to 9 June 2012 and March 2011 to September 2012, respectively. The core sample consisted of 24910 adults ( $\geq 18$ years old) and age was determined by the NHS or NNPAS interview date. We restricted our study to those who voluntarily participated in both TC and FPG tests $(\mathrm{n}=7499)$, yielding an overall response rate of $30.1 \%$. All participants provided written informed consent, and our study was approved by the School of Medicine Low Risk Ethical Review Committee in the University of Queensland (approval number 2016SOMILRE-0161).

\section{Life's Simple 7}

All modifiable metrics were divided into ideal and unideal status. The detailed classification criteria are shown in table 1. Based on the number of ideal metrics, participants were grouped into three CVH categories: inadequate (0-2), average (3-4) and optimal (5-7). ${ }^{11}$

\section{Outcome measurement}

The self-reported CVD prevalence was based on the 10th version of the International Classification of Diseases, codes I00-I99. To be more specific, our study treated angina, stroke, rheumatic heart disease, heart attack, heart failure, hypertension, hypotension, hardening of the arteries/atherosclerosis/arteriosclerosis, haemorrhoids, varicose veins, rapid or irregular heartbeats/ tachycardia/palpitations and any other participant self-entered I00-I99 conditions as CVD. Respondents were asked whether a doctor or a nurse has ever told them that they have those conditions, respectively. They were asked whether they currently have the condition if they have chosen yes to any of them. Those who have been told and currently have at least one of the above conditions were regarded as positive for CVD presence in our study.

\section{Covariates}

The following variables were adjusted as covariates in the present study: age, sex, educational attainment, income status and residence region. Educational attainment was categorised as high $(\geq 12$ school years) and low ( $<12$ school years). Income status was evaluated by household income and dichotomised as low ( $\leq 50$ th percentile equivalised weekly household income) and high ( $>50$ th percentile equivalised weekly household income). Residence region was classified into major cities, inner regional areas and other areas (outer regional and remote areas). 


\section{Statistical analysis}

First, we used univariate and multivariate Poisson regression analyses to calculate crude (unadjusted) and adjusted incidence rate ratios (IRRs) and corresponding 95\% CIs, and thus to elucidate the association between preventable factors and CVD occurrence.

Second, we calculated adjusted population attributable fractions (PAFs) based on the following equation to measure the effects of each component on CVD reduction. ${ }^{12} \mathrm{Pe}$ is the prevalence of exposure and rate ratios (RRs) were replaced with adjusted IRRs.

$$
P A F=\frac{P e \times(R R-1)}{1+P e \times(R R-1)}
$$

Third, we calculated ORs using logistic regression analyses to explore the relationship between overall CVH and CVD prevalence. Participants with missing values in one or more of Life's Simple 7 components were not included in the analyses.

To infer results for the total in-scope population, we used biomedical weight and jackknife method in the
Life's Simple 7 and CVD association analyses. We used person weight and jackknife method in characteristics comparisons between participants and non-participants. ${ }^{13}$ All analyses were conducted within the ABS's Remote Access Data Laboratory with Stata V.10.0. A two-sided p value $<0.05$ was used to determine statistical significance.

\section{RESULTS}

For the 7499 participants, 2100 are positive for CVD, with a weighted prevalence of $21.0 \%$. Among the seven metrics, FPG has the highest weighted ideal proportion $(83.6 \%)$, followed by smoking status (55.6\%), TC (45.5\%), blood pressure $(44.2 \%)$, BMI (39.2\%), physical activity (26.7\%) and dietary pattern $(4.8 \%)$. The metrics and covariates details of participants are summarised in table 2. The comparisons of the characteristics of participants and non-participants are listed in online supplementary table S1.

In the univariate analysis, all of the factors, except dietary pattern, are positively associated with CVD prevalence. The relationships still exist after adjusting for

Table 2 Characteristics of Life's Simple 7 and covariates in the current study

\begin{tabular}{|c|c|c|c|c|c|c|c|}
\hline \multirow[b]{2}{*}{ Variables } & \multirow[b]{2}{*}{ Status } & \multicolumn{2}{|c|}{ Having CVD } & \multicolumn{2}{|c|}{ Not having CVD } & \multicolumn{2}{|l|}{ Overall } \\
\hline & & $\mathrm{n} / \mathrm{N}$ & $\% *$ & $\mathrm{n} / \mathrm{N}$ & $\%^{*}$ & $n / N$ & $\% *$ \\
\hline \multirow[t]{2}{*}{ Smoking } & Ideal & $947 / 2100$ & 47.2 & 2815/5399 & 57.8 & $3762 / 7499$ & 55.6 \\
\hline & Unideal & $1153 / 2100$ & 52.8 & $2584 / 5399$ & 42.2 & $3737 / 7499$ & 44.4 \\
\hline \multirow[t]{2}{*}{ Body mass index } & Ideal & $462 / 1977$ & 25.2 & $1933 / 5150$ & 42.9 & $2395 / 7127$ & 39.2 \\
\hline & Unideal & $1515 / 1977$ & 74.8 & $3217 / 5150$ & 57.1 & $4732 / 7127$ & 60.8 \\
\hline \multirow[t]{2}{*}{ Physical activity } & Ideal & $326 / 2099$ & 16.0 & $1448 / 5396$ & 29.6 & $1774 / 7495$ & 26.7 \\
\hline & Unideal & $1773 / 2099$ & 84.0 & $3948 / 5396$ & 70.4 & $5721 / 7495$ & 73.3 \\
\hline \multirow[t]{2}{*}{ Dietary pattern } & Ideal & $141 / 2100$ & 5.4 & $293 / 5399$ & 4.6 & $434 / 7499$ & 4.8 \\
\hline & Unideal & $1959 / 2100$ & 94.7 & $5106 / 5399$ & 95.4 & $7065 / 7499$ & 95.2 \\
\hline \multirow[t]{2}{*}{ Total cholesterol } & Ideal & $506 / 2100$ & 28.0 & $2321 / 5399$ & 50.1 & $2827 / 7499$ & 45.5 \\
\hline & Unideal & $1594 / 2100$ & 72.0 & $3078 / 5399$ & 49.9 & $4672 / 7499$ & 54.5 \\
\hline \multirow[t]{2}{*}{ Blood pressure } & Ideal & $523 / 2019$ & 25.8 & $2305 / 5202$ & 49.1 & $2828 / 7221$ & 44.2 \\
\hline & Unideal & $1496 / 2019$ & 74.2 & $2897 / 5202$ & 50.9 & $4393 / 7221$ & 55.8 \\
\hline \multirow[t]{2}{*}{ Fasting plasma glucose } & Ideal & $1376 / 2100$ & 68.8 & $4563 / 5399$ & 87.6 & $5939 / 7499$ & 83.6 \\
\hline & Unideal & $724 / 2100$ & 31.2 & $836 / 5399$ & 12.4 & $1560 / 7499$ & 16.4 \\
\hline \multirow[t]{2}{*}{ Age } & $<60$ years & $753 / 2100$ & 40.8 & $4070 / 5399$ & 84.7 & $4823 / 7499$ & 75.5 \\
\hline & $\geq 60$ years & $1347 / 2100$ & 59.3 & $1329 / 5399$ & 15.3 & $2676 / 7499$ & 24.5 \\
\hline \multirow[t]{2}{*}{ Sex } & Male & $952 / 2100$ & 47.1 & $2377 / 5399$ & 49.9 & $3329 / 7499$ & 49.3 \\
\hline & Female & $1148 / 2100$ & 52.9 & $3022 / 5399$ & 50.1 & $4170 / 7499$ & 50.7 \\
\hline \multirow[t]{2}{*}{ Education level } & High & $682 / 2100$ & 35.7 & $3051 / 5399$ & 63.7 & $3733 / 7499$ & 57.9 \\
\hline & Low & $1418 / 2100$ & 64.3 & $2348 / 5399$ & 36.3 & $3766 / 7499$ & 42.1 \\
\hline \multirow[t]{2}{*}{ Income } & High & $674 / 1918$ & 36.1 & $2726 / 4899$ & 57.9 & $3400 / 6817$ & 53.2 \\
\hline & Low & $1244 / 1918$ & 63.9 & $2173 / 4899$ & 42.1 & $3417 / 6817$ & 46.8 \\
\hline \multirow[t]{3}{*}{ Region } & Major cities & $1184 / 2100$ & 66.7 & $3378 / 5399$ & 74.0 & $4562 / 7499$ & 72.5 \\
\hline & Inner regional & $553 / 2100$ & 23.1 & $1156 / 5399$ & 18.7 & $1709 / 7499$ & 19.6 \\
\hline & Other & $363 / 2100$ & 10.1 & $865 / 5399$ & 7.3 & $1228 / 7499$ & 7.9 \\
\hline
\end{tabular}

*Weighted prevalence using biomedical weight.

CVD, cardiovascular disease. 


\begin{tabular}{|c|c|c|c|c|}
\hline Variables & Crude IRR (95\% CI) & $\mathbf{p}$ & Adjusted* IRR (95\% CI) & $\mathbf{p}$ \\
\hline Smoking & 1.40 (1.24 to 1.58$)$ & $<0.01$ & 1.18 (1.04 to 1.34$)$ & 0.01 \\
\hline Elevated body mass index & 1.92 (1.64 to 2.24$)$ & $<0.01$ & 1.37 (1.21 to 1.55$)$ & $<0.01$ \\
\hline Physical inactivity & 1.91 (1.59 to 2.30$)$ & $<0.01$ & 1.23 (1.00 to 1.52$)$ & 0.049 \\
\hline Unideal dietary pattern & 0.88 (0.69 to 1.12$)$ & 0.29 & 1.13 (0.94 to 1.37$)$ & 0.19 \\
\hline Elevated total cholesterol & 2.14 (1.88 to 2.44$)$ & $<0.01$ & 1.21 (1.06 to 1.38$)$ & 0.01 \\
\hline Elevated blood pressure & 2.28 (1.96 to 2.66$)$ & $<0.01$ & 1.27 (1.10 to 1.47$)$ & $<0.01$ \\
\hline Elevated fasting plasma glucose & 2.32 (2.09 to 2.57 ) & $<0.01$ & 1.34 (1.21 to 1.49$)$ & $<0.01$ \\
\hline
\end{tabular}

*Adjusted for age, sex, educational attainment, income and residence region.

IRR, incidence rate ratio.

covariates. Raised BMI (adjusted IRR: 1.37; 95\% CI 1.21 to $1.55, \mathrm{p}<0.01$ ), elevated FPG (adjusted IRR: 1.34; $95 \%$ CI 1.21 to $1.49, \mathrm{p}<0.01$ ), increased blood pressure (adjusted IRR: 1.27 ; 95\% CI 1.10 to 1.47 , p $<0.01$ ), physical inactivity (adjusted IRR: 1.23; 95\% CI 1.00 to 1.52 , $\mathrm{p}=0.049$ ), unideal TC (adjusted IRR: 1.21; 95\% CI 1.06 to $1.38, \mathrm{p}=0.01$ ) and smoking (adjusted IRR: $1.18 ; 95 \%$ CI 1.04 to $1.34, \mathrm{p}=0.01$ ) are significantly associated with higher CVD risk (table 3). We calculated adjusted PAFs to quantify the contributions of certain factors to CVD prevalence (figure 1). Raised BMI is the largest significant contributor to CVD prevalence, with adjusted PAF of $20 \%$, followed by physical inactivity $(15 \%)$, increased blood pressure (14\%), unideal TC (12\%), smoking (8\%) and elevated FPG $(7 \%)$.

Table 4 displays the relationship between the number of ideal metrics and CVD prevalence. Compared with those in the inadequate category, those in the optimal category had a reduction of $66 \%$ in CVD risk (adjusted OR: $0.34 ; 95 \%$ CI 0.22 to 0.54 ), and those in the average category had a reduction of 33\% in CVD risk (adjusted OR: $0.67 ; 95 \%$ CI 0.56 to 0.81 ). On average, one more ideal metric was associated with a $21 \%$ reduced risk of CVD (adjusted OR: 0.79 ; 95\% CI 0.73 to 0.84 ). Additionally, higher numbers of ideal behaviours and factors are also associated with lower risk of CVD (online supplementary table S2 and supplementary table S3).

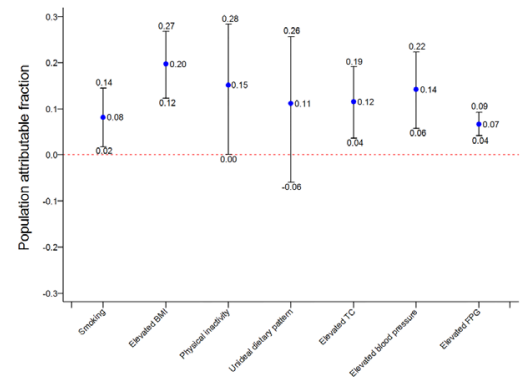

Figure 1 Adjusted population attributable fractions of each component of Life's Simple 7 to cardiovascular disease. BMI, body mass index; FPG, fasting plasma glucose; TC, total cholesterol.

\section{DISCUSSION}

To the best of our knowledge, it is the first study that explored the individual and combined effects of Life's Simple 7 on CVD prevalence among general non-indigenous Australians. We observed that raised BMI, physical inactivity, increased blood pressure, unideal TC, smoking and elevated FPG are independent risk factors and contributors of CVD. Higher number of ideal metrics is associated with reduced CVD risk.

Raised BMI was the largest contributor to CVD risk in our study. Several previous reports also identified overweight/obesity as a significant risk factor of CVD. ${ }^{14-16}$ Moreover, it has been reported that the prevalence of obese is still increasing over time. In Australia, the age-standardised obesity prevalence has more than doubled from 1980 to $2000 .{ }^{17}$ Similar increased trends in overweight and/or obesity were also observed in adults from China, ${ }^{18} \mathrm{USA}^{19}{ }^{19}$ Mongalia ${ }^{20}$ and Poland. ${ }^{21}$ Additionally, we noticed that unideal status of physical activity, blood pressure, TC, smoking and FPG are also significant contributors to CVD presence in our study. Their roles in elevating the CVD risks have also been confirmed in a number of studies, ${ }^{9} 142223$ which suggested that relevant intervention programmes are needed to improve CVH.

Similar to our findings, two US studies also identified BMI as the most crucial contributor to coronary artery calcification ${ }^{24}$ and venous thromboembolism, ${ }^{25}$ respectively, while a number of studies from USA, ${ }^{1126-28}$ China $^{9}$ 1416 and Korea ${ }^{10}$ ranked unideal blood pressure as the most significant contributor of CVD mortality, ${ }^{9-11} 2627$ CVD incidence ${ }^{14}$ and stroke incidence. ${ }^{1628}$ The inconsistency in rankings may be suggestive of the various risk factor patterns of different diseases and populations.

Dietary pattern was not independently related to CVD reduction in the current study. Several studies have identified dietary pattern ${ }^{1429}{ }^{30}$ as a CVD risk factor. However, some studies failed to reveal the association. ${ }^{102}$ A possible explanation of the conflicting findings may be due to the various definitions of dietary pattern status in each study. Thus, more studies are warranted to test the relationship more accurately. 
Table 4 Number of ideal metrics and CVD presence

\begin{tabular}{llllll}
\hline Ideal metrics number & CVD cases/participants & Crude OR (95\% Cl) & $\mathbf{p}$ & Adjusted* OR (95\% Cl) & $\mathbf{p}$ \\
\hline $0-2$ & $1283 / 3342$ & Referent & - & Referent & - \\
$3-4$ & $585 / 2786$ & $0.41(0.35$ to 0.48$)$ & $<0.01$ & $0.67(0.56$ to 0.81$)$ & $<0.01$ \\
$5-7$ & $70 / 874$ & $0.09(0.06$ to 0.14$)$ & $<0.01$ & $0.34(0.22$ to 0.54$)$ & $<0.01$ \\
One more ideal metric & - & $0.60(0.57$ to 0.63$)$ & $<0.01$ & $0.79(0.73$ to 0.84$)$ & $<0.01$ \\
\hline
\end{tabular}

${ }^{*}$ Adjusted for age, sex, educational attainment, income and residence region.

CVD, cardiovascular disease.

We have observed that CVD prevalence showed declining trends with increasing number of ideal CVH metrics, behaviours and factors. Our findings are consistent with several studies that also found the graded inverse relationship between favourable ideal metrics and CVD mortality ${ }^{61126}$ and incidence. ${ }^{52225}$ 28 Our results, along with those of previous studies, suggested that those factors may interrelate with each other and a small improvement of $\mathrm{CVH}$ might have a dramatic reduction in CVD burden.

There are some limitations to our study. First, it is a cross-sectional study and we are unable to examine temporality between Life's Simple 7 and CVD incidence or mortality. Second, we used modified metrics definitions owing to AHS data set structures, and some variables, like dietary evaluation and smoking status, were self-reported and thus may not be completely accurate. Third, the sample excluded those living in very remote areas and indigenous communities, although their population proportion is very small. Additionally, for some characteristics, there are some differences between those with and without TC and FPG samples (online supplementary table S1). Although our findings are representative of the target population by using the biomedical weight, we may still have the risk of selection bias.

In summary, we identified raised BMI, increased blood pressure, physical inactivity, unideal TC, smoking and elevated FPG as significant risk factors and contributors of CVD presence in the general Australians. The higher number of ideal Life's Simple 7 metrics was associated with reduced risk of CVD.

Contributors YP and ZW: concept/design. YP: data analysis/interpretation, drafting article. ZW: critical revision of article. YP and ZW: approval of article.

Funding This study was supported by the University of Queensland International Scholarship (No 44078179) to YP and the National Health and Medical Research Council of Australia (No APP1042343) to ZW. The funders had no role in study design, data collection and analysis, decision to publish or preparation of the manuscript.

Competing interests None declared.

Patient consent Obtained.

Ethics approval The School of Medicine Low Risk Ethical Review Committee in the University of Queensland.

Provenance and peer review Not commissioned; internally peer reviewed.

Data sharing statement Any requests for data sharing should be made to the corresponding author.

Open Access This is an Open Access article distributed in accordance with the Creative Commons Attribution Non Commercial (CC BY-NC 4.0) license, which permits others to distribute, remix, adapt, build upon this work non-commercially, and license their derivative works on different terms, provided the original work is properly cited and the use is non-commercial. See: http://creativecommons.org/ licenses/by-nc/4.0/

(C) Article author(s) (or their employer(s) unless otherwise stated in the text of the article) 2017. All rights reserved. No commercial use is permitted unless otherwise expressly granted.

\section{REFERENCES}

1. Mozaffarian D, Benjamin EJ, Go AS, et al. Heart Disease and Stroke Statistics-2016 Update: a Report from the American Heart Association. Circulation 2016;133:e38-60.

2. GBD. Morality and causes of Death Collaborators. Global, regional, and national age-sex specific all-cause and cause-specific mortality for 240 causes of death, 1990-2013: a systematic analysis for the global burden of disease study 2013. Lancet 2015;385:117-71.

3. Lozano R, Naghavi M, Foreman K, et al. Global and regional mortality from 235 causes of death for 20 age groups in 1990 and 2010: a systematic analysis for the Global Burden of Disease Study 2010. Lancet 2012;380:2095-128.

4. Lloyd-Jones DM, Hong Y, Labarthe D, et al. . Defining and setting national goals for cardiovascular health promotion and disease reduction: the American Heart Association's strategic Impact Goal through 2020 and beyond. Circulation 2010;121:586-613.

5. Folsom AR, Yatsuya $\mathrm{H}$, Nettleton JA, et al. Community prevalence of ideal cardiovascular health, by the american Heart Association definition, and relationship with cardiovascular disease incidence. $J$ Am Coll Cardiol 2011;57:1690-6.

6. Dong C, Rundek T, Wright CB, et al. Ideal cardiovascular health predicts lower risks of myocardial infarction, stroke, and vascular death across whites, blacks, and hispanics: the northern Manhattan study. Circulation 2012;125:2975-84.

7. Saleem Y, DeFina LF, Radford NB, et al. Association of a favorable cardiovascular health profile with the presence of coronary artery calcification. Circ Cardiovasc Imaging 2015;8 e001851.

8. Aatola $\mathrm{H}$, Hutri-Kähönen $\mathrm{N}$, Juonala $\mathrm{M}$, et al. Prospective relationship of change in ideal cardiovascular health status and arterial stiffness: the Cardiovascular Risk in Young Finns Study. J Am Heart Assoc 2014;3:e000532.

9. Liu Y, Chi HJ, Cui LF, et al. The ideal cardiovascular health metrics associated inversely with mortality from all causes and from cardiovascular diseases among adults in a Northern Chinese industrial city. PLoS One 2014;9:e89161

10. Kim JY, Ko YJ, Rhee CW, et al. Cardiovascular health metrics and all-cause and cardiovascular disease mortality among middle-aged men in Korea: the Seoul male cohort study. J Prev Med Public Health 2013;46:319-28.

11. Artero EG, España-Romero V, Lee DC, et al. Ideal cardiovascular health and mortality: Aerobics Center Longitudinal Study. Mayo Clin Proc 2012;87:944-52.

12. Hildebrandt M, Bender R, Gehrmann U, et al. Calculating confidence intervals for impact numbers. BMC Med Res Methodol 2006;6:32.

13. Australian Bureau of Statistics. Australian Health Survey: Users' Guide, 2011-13. 2013; http://www.abs.gov.au/ausstats/abs@.nsf/ Lookup/74D87E30B3539C53CA257BBB0014BB36?opendocument.

14. Wu S, Huang Z, Yang X, et al. Prevalence of ideal cardiovascular health and its relationship with the 4-year cardiovascular events in a northern Chinese industrial city. Circ Cardiovasc Qual Outcomes 2012;5:487-93.

15. Schnohr P, Marott JL, Kristensen TS, et al. Ranking of psychosocial and traditional risk factors by importance for coronary heart disease: the Copenhagen City Heart Study. Eur Heart J 2015;36:1385-93. 
16. Zhang Q, Zhou Y, Gao X, et al. Ideal cardiovascular health metrics and the risks of ischemic and intracerebral hemorrhagic stroke. Stroke 2013;44:2451-6.

17. Cameron AJ, Welborn TA, Zimmet PZ, et al. Overweight and obesity in Australia: the 1999-2000 Australian Diabetes, Obesity and Lifestyle Study (AusDiab). Med J Aust 2003;178:427-32.

18. Mi YJ, Zhang B, Wang HJ, et al. Prevalence and Secular Trends in Obesity Among Chinese Adults, 1991-2011. Am J Prev Med 2015;49:661-9.

19. Flegal KM, Carroll MD, Kit BK, et al. Prevalence of obesity and trends in the distribution of body mass index among US adults, 1999-2010. JAMA 2012;307:491-7.

20. Chimeddamba O, Gearon E, Stevenson C, et al. Trends in adult overweight and obesity prevalence in Mongolia, 2005-2013. Obesity 2016;24:2194-201.

21. Lipowicz A, Łopuszańska M, Kołodziej $H$, et al. Secular trends in BM and the prevalence of obesity in young Polish males from 1965 to 2010. Eur J Public Health 2015;25:279-82.

22. Miao C, Bao M, Xing A, et al. Cardiovascular Health Score and the Risk of Cardiovascular Diseases. PLoS One 2015;10:e0131537.

23. O'Donnell MJ, Xavier D, Liu L, et al. Risk factors for ischaemic and intracerebral haemorrhagic stroke in 22 countries (the INTERSTROKE study): a case-control study. Lancet 2010;376:112-23.
24. Alman AC, Maahs DM, Rewers MJ, et al. Ideal cardiovascular health and the prevalence and progression of coronary artery calcification in adults with and without type 1 diabetes. Diabetes Care 2014;37:521-8.

25. Olson NC, Cushman M, Judd SE, et al. American Heart Association's Life's Simple 7 and risk of venous thromboembolism: the Reasons for Geographic and Racial Differences in Stroke (REGARDS) study. J Am Heart Assoc 2015;4:e001494.

26. Ford ES, Greenlund KJ, Hong Y. Ideal cardiovascular health and mortality from all causes and diseases of the circulatory system among adults in the United States. Circulation 2012;125:987-95.

27. Yang Q, Cogswell ME, Flanders WD, et al. Trends in cardiovascular health metrics and associations with all-cause and CVD mortality among US adults. JAMA 2012;307:1273-83.

28. Kulshreshtha A, Vaccarino V, Judd SE, et al. Life's Simple 7 and risk of incident stroke: the reasons for geographic and racial differences in stroke study. Stroke 2013;44:1909-14.

29. Miedema MD, Petrone A, Shikany JM, et al. Association of Fruit and Vegetable Consumption During Early Adulthood With the Prevalence of Coronary Artery Calcium After 20 Years of Follow-Up: The Coronary Artery Risk Development in Young Adults (CARDIA) Study. Circulation 2015;132:1990-8.

30. O'Flaherty M, Bandosz P, Critchley J, et al. Euroheart II Steering Group. Exploring potential mortality reductions in 9 European countries by improving diet and lifestyle: A modelling approach. Int $J$ Cardiol 2016:207:286-91. 